\title{
Polymorphic variation in surfactant protein $B$ is associated with COPD exacerbations
}

\author{
M.G. Foreman*, D.L. DeMeo*\#, C.P. Hersh*,\#, V.J. Carey*, V.S. Fan`, J.J. Reilly", \\ S.D. Shapiro ${ }^{+}$and E.K. Silverman*,\#
}

ABSTRACT: Exacerbations of chronic obstructive pulmonary disease (COPD) reduce quality of life and increase mortality. Genetic variation might explain the substantial variability seen in exacerbation frequency among COPD subjects with similar lung function. Polymorphisms in five candidate genes, previously associated with COPD susceptibility, were analysed in order to determine whether they demonstrated association with COPD exacerbations.

A total of 88 single nucleotide polymorphisms (SNPs) in the genes microsomal epoxide hydrolase (EPHX1), transforming growth factor, beta-1 (TGFB1), serpin peptidase inhibitor, clade E (nexin, plasminogen activator inhibitor type 1), member 2 (SERPINE2), glutathione S-transferase pi (GSTP1) and surfactant protein B (SFTPB) were genotyped in 389 non-Hispanic white participants in the National Emphysema Treatment Trial. Exacerbations were defined as COPDrelated emergency room visits or hospitalisations using the Centers for Medicare and Medicaid Services claims data.

One or more exacerbations were experienced by $216(56 \%)$ subjects during the study period. An SFTPB promoter polymorphism, rs3024791, was associated with COPD exacerbations. Logistic regression models, analysing a binary outcome of presence or absence of exacerbations, confirmed the association of rs3024791 with COPD exacerbations. Negative binomial regression models demonstrated association of multiple SFTPB SNPs (rs2118177, rs2304566, rs1130866 and rs3024791) with exacerbation rates. Polymorphisms in EPHX1, GSTP1, TGFB1 and SERPINE2 did not demonstrate association with COPD exacerbations.

In conclusion, genetic variation in surfactant protein B is associated with chronic obstructive pulmonary disease susceptibility and exacerbation frequency.

KEYWORDS: Association analysis, chronic obstructive pulmonary disease, exacerbations, genetics, single nucleotide polymorphisms, surfactant protein B

T he Global Initiative for Chronic Obstructive Lung Disease (GOLD) defines chronic obstructive pulmonary disease (COPD) exacerbations as "acute events within the natural course of the disease that exceed daily variation in baseline dyspnoea, cough and/or sputum that may merit a change in regular medication" [1]. COPD exacerbations are associated with a range of outcomes, from slightly worsening respiratory symptoms to death. Frequent COPD exacerbations may hasten decline in lung function [2, 3] and increase mortality [4]. COPD exacerbations have a substantial personal $[5,6]$ and public impact $[7,8]$, which includes reduction in quality of life, loss of wages and increased healthcare costs. Exacerbations resulting in hospitalisation are responsible for the greatest proportion of healthcare costs related to COPD [8-10]. Efforts to reduce or prevent COPD exacerbations, particularly those associated with hospitalisations, would dramatically improve the health status of COPD subjects and diminish the economic burden imposed by the disease.

Genetic determinants of COPD exacerbations have not been clearly identified [11, 12] despite the observation that COPD exacerbations are more frequent in individuals with prior exacerbations. Variation in exacerbation frequency could relate to different COPD subtypes or to differential susceptibility to infection. The present authors hypothesised that genetic variation, associated with COPD susceptibility, might
AFFILIATIONS

*Channing Laboratory, Brigham and Women's Hospital, and Harvard Medical School,

\#Pulmonary and Critical Care Division, Brigham and Women's Hospital, Boston, MA

"Dept of Pulmonary and Critical Care, University of Washington, Seattle, WA, and

${ }^{+}$Dept of Medicine, University of Pittsburgh School of Medicine, Pittsburgh, PA, USA.

\section{CORRESPONDENCE}

E.K. Silverman, Channing Laboratory, 181 Longwood Ave., Boston, MA

02115, USA

Fax: 16175250958

E-mail: edwin.silverman@

channing.harvard.edu

Received:

March 152008

Accepted after revision:

May 282008

SUPPORT STATEMENT

The presentstudy wasfunded with grants, HL007427, HL075478, HL71393 and HL082541, from the NIH. D.L. DeMeo was funded by NIH-KO8 and HL072918. C.P. Hersh was funded by $\mathrm{NIH-K08}$ and HL080242. The National Emphysema Treatment Trial (NETT) was supported by contracts with the National Heart, Lung, and Blood Institute (N01HR76101, N01HR76102, N01HR76103, N01HR76104, N01HR76105, N01HR76106, N01HR76107 N01HR76108, N01HR76109 N01HR76110, N01HR76111, N01HR76112, N01HR76113, N01HR76114, N01HR76115 N01HR76116, N01HR76118 and N01HR76119), the Centers for Medicare and Medicaid Services and the Agency for Healthcare Research and Quality. 
influence the occurrence and frequency of COPD exacerbations. In order to test this hypothesis, 88 single nucleotide polymorphisms (SNPs) in five genes, previously associated with COPD susceptibility in at least two studies, were analysed for association with COPD exacerbations [13, 14].

\section{MATERIALS AND METHODS Study participants}

389 non-Hispanic white subjects, without severe $\alpha-1$ antitrypsin deficiency, enrolled in the National Emphysema Treatment Trial (NETT) Genetics Ancillary Study were included in the present study. The NETT study was a multi-centre, randomised, clinical trial comparing conventional medical therapy for severe emphysema to lung volume reduction surgery (LVRS) [15-17]. Briefly, eligibility criteria for participation in the NETT were as follows: 1) forced expiratory volume in one second $(\mathrm{FEV} 1) \leqslant 45 \%$ predicted; 2 ) evidence of hyperinflation manifested by an elevated total lung capacity and residual volume on pulmonary function testing; 3) bilateral emphysema on high-resolution computed tomography scanning of the chest; and 4) successful completion of predetermined performance goals during pulmonary rehabilitation. Active cigarette smoking was an exclusion criterion [16]. As the purpose of the present study was to determine the role of genetic influences on the susceptibility to or the frequency of COPD exacerbations, nine individuals who were randomised to LVRS but did not undergo surgery were considered as medically treated in the analyses.

\section{Data collection}

Information regarding COPD-related emergency room visits or hospitalisations was available for an 8-yr study period. Enrolment into NETT began in January 1998. Exacerbation event data were collected for all participants beginning $1 \mathrm{yr}$ prior to randomisation from claims records of the Centers for Medicare and Medicaid Services (CMS; Baltimore, MD, USA). Visit records with a principal International Classification of Diseases, 9th Revision, Clinical Modification diagnosis code of 491, 492, 493 or 496 were eligible for inclusion. Emergency room visits and hospitalisations on the same calendar date were considered as one event. Independent emergency room visits and hospitalisations separated by a period of $\geqslant 14$ days were included as unique events. The BODE (body mass index (BMI), airflow obstruction, dyspnoea and exercise capacity) index [18], a composite multi-dimensional score, was modified to include the post-pulmonary rehabilitation FEV1 values, 6min walk test, BMI and the University of California, San Diego, Pulmonary Rehabilitation Shortness-of-Breath Questionnaire [19]. The co-morbidity score was derived from the Charlson comorbidity index that has been modified for use with administrative data.

\section{SNP selection and genotyping}

Detailed procedural descriptions of the genotyping and SNP selection for microsomal epoxide hydrolase (EPHX1), glutathione S-transferase pi (GSTP1), surfactant protein B (SFTPB) $[13,20]$, serpin peptidase inhibitor, clade E (nexin, plasminogen activator inhibitor type 1), member 2 (SERPINE2) [14] and transforming growth factor, beta-1 (TGFB1) [21] have been previously published. Briefly, genotype data for European Americans (database code: CEU) from the SeattleSNPs
Program for Genomic Applications [22] and the International HapMap Project [23] were used to select linkage disequilibrium-tagging SNPs for all five genes. Pairwise linkage disequilibrium (LD)-tagging was achieved using Tagger [24] for SNPs with a minimum minor allele frequency of 0.1 and an $\mathrm{r}^{2}$ of 0.9 . Additional SNPs in SERPINE2 were obtained by DNA sequencing of all exons and exon-intron boundaries [14]. Three platforms were used for genotyping: allele specific hybridisation assay (Illumina Golden Gate, San Diego, CA, USA); the $5^{\prime}$ to $3^{\prime}$ exonuclease assay (TaqMan; Applied Biosystems, Foster City, CA, USA); or unlabelled minisequencing reactions and mass spectrometry (Sequenom, San Diego). All polymorphisms analysed in the five candidate genes are listed in the online data supplement (table S1). The LD map of the five SNPS in SFTPB was created using Haploview [25].

\section{Statistical analysis}

Quantitative data with a normal distribution are presented as mean \pm SD. Variables with a non-normal distribution are presented as median \pm interquartile ranges. Polymorphisms with significant $(\mathrm{p} \leqslant 0.05)$ Cochran-Armitage, a genotypebased test for association (SAS/Genetics; Cary, NC, USA), tests for trend [26] were entered into multivariable logistic regression models. The logistic regression models for probability of any exacerbation analysed linear trends with additive genetic coding. The models were adjusted for the following potential confounders: age, FEV1 \% pred, smoking history in pack-yrs, sex (using male $=1$ and female $=0$ ), surgery status (using underwent LVRS $=1$ and received medical therapy $=0$ ), and surgery-by-genotype interaction. There were no significant surgery-by-genotype interactions and the interaction terms were not included in the final models. Additionally, there were no significant genotype-by-smoking interactions. Therefore, interaction terms composed of the genotypes and pack-yrs of smoking were not retained in the models. CMS-claims data were available for the period 1997-2004. COPD exacerbations noted in NETT appeared to follow a negative binomial distribution. In order to analyse exacerbation rates, account for correlated data in the form of multiple exacerbations in a single individual and allow for a differential effect of medical therapy versus LVRS on exacerbation frequency, negative binomial regression models were constructed. The negative binomial models, accounting for varying observation times, were constructed under an additive mode of inheritance and were adjusted for age, FEV1 \% pred, pack-yrs smoking and surgery. The multi-state models assumed no difference between the treatment groups prior to randomisation. In order to determine if surgical treatment influenced the frequency of exacerbations, exacerbation counts were compared in the surgical patients after LVRS and after randomisation in medical patients. There were no significant surgery-bygenotype interactions in the negative binomial models and the interaction terms were removed from the final models. Haplotype analysis was performed on haplotypes with $\geqslant 5 \%$ frequency using the haplo.stats [27] package in $\mathrm{R}$ (version 2.5.1). The sliding window haplotype analysis assessed adjacent 2-, 3- or 4-loci combinations. Empirical p-values for significant global haplotype and sliding window analyses were obtained through permutation of the p-values with 1,000 simulations. The haplotype analysis was adjusted for age, sex, 
FEV1 \% pred, pack-yrs smoking and treatment. All SFTPB and TGFB1 SNPs were in Hardy-Weinberg equilibrium. Two GSTP1 SNPs, one EPHX1 SNP, and one SERPINE2 SNP were out of Hardy-Weinberg equilibrium and were removed from further analysis.

\section{RESULTS}

The demographic and clinical characteristics of the NETT participants are displayed in table 1 . Over the period of study, COPD exacerbations, defined as COPD-related emergency department visits or hospitalisations, occurred in $56 \%$ of the subjects. Detailed characterisations of the epidemiological predictors of exacerbations in NETT participants have been reported elsewhere [28, 29].

Cochran-Armitage trend tests for SNPs in EPHX1, TGFB1, GSTP1 and SERPINE2 were not significant. These genes were not analysed further. The SFTPB genotype frequencies for study participants are displayed in table 2. Pairwise LD was determined for the five SFTPB SNPs by $\mathrm{r}^{2}$ (fig. 1). There was generally low LD between the SFTPB SNPs. The highest $\mathrm{r}^{2}$ was 0.6 between rs211877 and rs2304566.

One SNP in SFTPB, rs3024791, a promoter polymorphism, was significantly associated with probability of any exacerbation in the unadjusted Cochran-Armitage trend test $(p=0.008)$. Cochran-Armitage trend tests were non-significant for the remaining SFTPB SNPs (table 3).

After adjustment for potentially relevant clinical confounders, such as age, sex, FEV1, smoking history, medical versus surgical treatment and follow-up time, having more copies of the minor allele of rs3024791, (odds ratio (OR) 0.6, 95\% confidence interval (CI) $0.4-0.9 ; \mathrm{p}=0.007$ ) was associated with a reduction in the odds of experiencing COPD exacerbations, independent of the treatment effect (table 4).

\begin{tabular}{ll}
\hline TABLE 1 & $\begin{array}{l}\text { Demographic characteristics of surfactant } \\
\text { protein B single nucleotide polymorphisms in } \\
\text { 389 National Emphysema Treatment Trial } \\
\text { subjects }\end{array}$ \\
& \\
Age yrs & $67 \pm 6$ \\
Smoking history pack-yrs & $66 \pm 30$ \\
Post-BD FEV $\mathbf{1} \%$ pred & $28 \pm 7$ \\
Modified BODE index & $5 \pm 3$ \\
Male sex & 64 \\
LVRS & 53 \\
Exacerbations $>\mathbf{1}^{\#}$ & 56 \\
Bronchodilator therapy & 99 \\
Inhaled corticosteroid therapy & 71 \\
Inhaled anticholinergic therapy & 82 \\
Current systemic corticosteroid therapy & 24 \\
\hline
\end{tabular}

Data are presented as mean \pm SD or \%, apart from modified body mass index, airflow obstruction, dyspnoea and exercise capacity (BODE) index which is presented as median \pm interquartile range. BD: bronchodilator administration; FEV1: forced expiratory volume in one second; \% pred: \% predicted; IQR: interquartile range; LVRS: lung volume reduction surgery. ${ }^{*}$ : exacerbations ranged 0-29 events per subject.
Enrolment into the NETT study occurred between January 1998 and July 2002. Enrolment during the latter years of the study resulted in only 29 months for CMS data to accrue postrandomisation. In order to account for variable follow-up time, an initial analysis of claims data was limited to $3.3 \mathrm{yrs}(1 \mathrm{yr}$ prior and 2.3 yrs after randomisation) in the logistic regression models. Seven individuals had $<2.3$ yrs of follow-up time; however, all seven died after randomisation. Their data were not excluded from this analysis. Controlling for relevant covariates in an additive model, the T allele of rs3024791 was still significantly associated with a reduction in the odds of COPD exacerbations (OR 0.6, 95\% CI 0.4-0.9; $\mathrm{p}=0.02$ ).

Of the 389 study subjects in the 8-yr period of study, 216 (56\%) participants experienced 575 exacerbation events, resulting in an overall exacerbation rate of 0.29 events $\cdot$ person- $\mathrm{yr}^{-1}$. The majority of the cohort experienced $\leqslant 4$ events (median (interquartile range; IQR) 1 (2) events). Stratified by medical versus surgical treatment, $183(47 \%)$ subjects were treated nonsurgically and 206 (53\%) subjects underwent LVRS. In the medical group, 110 subjects experienced 307 exacerbations resulting in 0.32 events person- $\mathrm{yr}^{-1}$ in the medical arm. In the surgically treated group, 106 subjects experienced 268 exacerbations resulting in an exacerbation frequency of 0.25 events person$\mathrm{yr}^{-1}$ in the surgical arm. Delayed surgical therapy could artificially affect the exacerbation frequency by reducing the number of exacerbations experienced during the post-operative period. Most individuals, however, underwent LVRS soon after randomisation. The median (IQR) time to LVRS in this exacerbation cohort was 11 (6) days. LVRS was performed in these subjects within 20 days (90th percentile).

\begin{tabular}{lccc} 
TABLE 2 & $\begin{array}{l}\text { Genotype frequencies for surfactant protein B } \\
\text { single nucleotide polymorphisms (SNPs) in } 389 \\
\text { non-Hispanic white chronic obstructive } \\
\text { pulmonary disease subjects }\end{array}$ \\
SNP & Genotype & Count & Frequency \\
\hline \multirow{2}{*}{ rs2118177 } & $\mathrm{C} / \mathrm{C}$ & 55 & \\
& $\mathrm{~T} / \mathrm{C}$ & 159 & 0.14 \\
rs2304566 & $\mathrm{T} / \mathrm{T}$ & 166 & 0.42 \\
& $\mathrm{G} / \mathrm{G}$ & 28 & 0.44 \\
& $\mathrm{~A} / \mathrm{G}$ & 139 & 0.07 \\
rs1130866 & $\mathrm{A} / \mathrm{A}$ & 214 & 0.37 \\
& $\mathrm{~T} / \mathrm{T}$ & 113 & 0.56 \\
& $\mathrm{~T} / \mathrm{C}$ & 189 & 0.29 \\
rs2077079 & $\mathrm{C} / \mathrm{C}$ & 85 & 0.49 \\
& $\mathrm{C} / \mathrm{C}$ & 52 & 0.22 \\
& $\mathrm{~A} / \mathrm{C}$ & 176 & 0.14 \\
rs3024791 & $\mathrm{A} / \mathrm{A}$ & 143 & 0.47 \\
& $\mathrm{G} / \mathrm{G}$ & 276 & 0.39 \\
& $\mathrm{G} / \mathrm{A}$ & 94 & 0.73 \\
& $\mathrm{~A} / \mathrm{A}$ & 9 & 0.25 \\
& & & 0.02 \\
\hline
\end{tabular}

Genotype counts do not sum to 389 due to the following missing genotypes: nine for rs2118177, eight for rs2304566, two for rs1130866, eight for rs2077079 and 10 for rs 3024791 . 


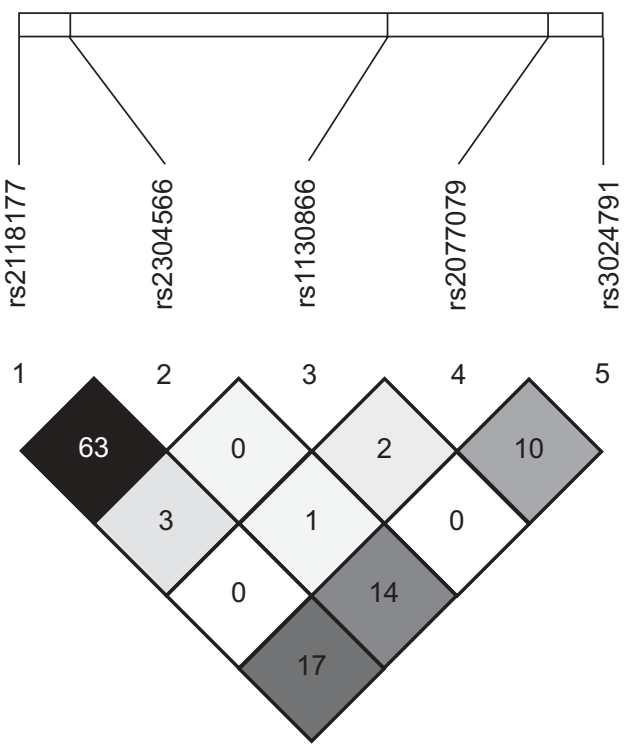

FIGURE 1. Linkage disequilibrium map for five surfactant protein B single nucleotide polymorphisms in 389 National Emphysema Treatment Trial Subjects. Darker blocks correspond to higher $r^{2}$ values. Pairwise $r^{2}$ values multiplied by 100 are shown

In the negative binomial models (table 5), four of the five SNPs in SFTPB were significantly associated with COPD exacerbation counts. The negative binomial models were constructed with additive genetic coding and adjusted for age, sex, lung function, smoking history pack-yrs and treatment. Inheritance of one or more copies of minor alleles of the following variants was associated with a reduction in exacerbation counts: rs2118177, rs2304566, rs1130866 and rs3024791 (fig. 2). The findings were robust with models constructed with exacerbations separated by 30 days, truncating follow-up at 4 yrs or using the entire CMS data collected over 8 yrs.

For the binary exacerbations phenotype (exacerbations or no exacerbations), haplotype analysis was performed on SFTPB haplotypes with $\geqslant 5 \%$ frequency. The global haplotype score p-value for all five SNPs, based on 1,000 simulations, was 0.03. The C-G-C-A-A haplotype (rs2118177-rs2304566-rs1130866rs2077079-rs3024791) had the strongest significance $(p=0.009)$ and a frequency of $6 \%$. Sliding window haplotype analysis was performed with empirical p-values determined by simulation.

\begin{tabular}{|c|c|c|c|c|}
\hline \multirow{2}{*}{$\begin{array}{l}\text { TABLE } 4 \\
\text { SNP }\end{array}$} & \multicolumn{4}{|c|}{$\begin{array}{l}\text { Multivariable logistic regression analysis }{ }^{\#} \text { for } \\
\text { probability of any exacerbation }\end{array}$} \\
\hline & $\begin{array}{l}\text { Unadjusted OR } \\
\qquad(95 \% \mathrm{Cl})\end{array}$ & $\mathrm{p}$-value & $\begin{array}{l}\text { Adjusted OR } \\
(95 \% \mathrm{Cl})\end{array}$ & $\mathrm{p}$-value \\
\hline rs2118177 & $0.8(0.6-1.1)$ & 0.1 & $0.8(0.6-1.1)$ & 0.2 \\
\hline rs2304566 & $0.8(0.6-1.1)$ & 0.1 & $0.8(0.5-1.1)$ & 0.1 \\
\hline rs1130866 & $0.8(0.6-1.1)$ & 0.1 & $0.8(0.6-1.1)$ & 0.1 \\
\hline rs2077079 & $1.2(0.9-1.7)$ & 0.2 & $1.2(0.9-1.6)$ & 0.3 \\
\hline rs3024791 & $0.6(0.4-0.9)$ & 0.008 & $0.6(0.4-0.9)$ & 0.007 \\
\hline \multicolumn{5}{|c|}{$\begin{array}{l}\text { SNP: single nucleotide polymorphism; OR: odds ratio; } \mathrm{Cl} \text { : confidence interval. } \\
\text { \#: adjusted for age, sex, smoking history pack-yrs, forced expiratory volume in } \\
\text { one second \% predicted and treatment; ": } 216 \text { National Emphysema Treatment } \\
\text { Trial subjects with at least one exacerbation and } 575 \text { total chronic obstructive } \\
\text { oulmonary disease exacerbations. }\end{array}$} \\
\hline
\end{tabular}

The strongest association was observed for the two-loci SNP haplotype (rs2077079-rs3024791; $\mathrm{p}=0.006$ ); however, haplotypes with three loci (rs1130866-rs2077079-rs3024791; $\mathrm{p}=0.01$ ) and four loci (rs2304566-rs1130866-rs2077079-rs3024791; $\mathrm{p}=0.01$ ) were also significant. An adjusted global haplotype score for all SNPs was calculated with the following covariates: age, sex, lung function, smoking history pack-yrs and treatment received. After 1,000 simulations, the adjusted global haplotype $\mathrm{p}$-value was 0.03 .

\section{DISCUSSION}

The adverse consequences of COPD exacerbations are varied: alteration in quality of life; increased healthcare costs and utilisation; accelerated lung function decline; and increased mortality. In the present study, it has been demonstrated, in individuals with severe chronic airflow limitation, that polymorphisms in SFTPB are associated with susceptibility to COPD exacerbations, which are substantial enough to warrant emergency department care or hospitalisations. It has also been demonstrated that polymorphisms in SFTPB are associated with exacerbation frequency. There are few studies of the genetic determinants of COPD exacerbations. YANG et al. [11] analysed the relationship of a polymorphism in mannose binding lectin (MBL2) to COPD exacerbations, COPD susceptibility and mannose binding lectin levels. In that 2-yr retrospective study, the MBL2 codon $54 \mathrm{~B}$ allele was associated with

\section{TABLE 3 Association analysis of surfactant protein B single nucleotide polymorphisms (SNPs) for probability of any chronic} obstructive pulmonary disease exacerbation

\begin{tabular}{lcccc}
\multicolumn{2}{c}{ Allele frequency } & & & p-value \\
\cline { 2 - 4 } & Nonexacerbators & Exacerbators & Allele Test & Armitage Trend Test \\
rs2118177 & 0.39 & 0.33 & 0.11 & 0.13 \\
rs2304566 & 0.29 & 0.23 & 0.10 & 0.10 \\
rs1130866 & 0.50 & 0.44 & 0.10 & 0.10 \\
rs2077079 & 0.35 & 0.40 & 0.20 & 0.20 \\
rs3024791 & 0.19 & 0.12 & 0.007 & 0.008 \\
\hline
\end{tabular}




\begin{tabular}{|c|c|c|c|c|}
\hline \multirow[t]{2}{*}{ TABLE 5} & \multicolumn{4}{|c|}{$\begin{array}{l}\text { gative binomial regression of chronic } \\
\text { structive pulmonary disease exacerbation } \\
\text { es }\end{array}$} \\
\hline & Estimate & $\begin{array}{l}\text { Standard } \\
\text { error }\end{array}$ & $95 \% \mathrm{Cl}$ & $\mathrm{p}$-value \\
\hline rs2118177 & -0.30 & 0.12 & $-0.5--0.07$ & 0.01 \\
\hline Age & -0.03 & 0.01 & $-0.05--0.005$ & 0.02 \\
\hline FEV $1 \%$ pred & -0.03 & 0.01 & $-0.05--0.01$ & 0.01 \\
\hline Treatment group ${ }^{\#}$ & -0.55 & 0.19 & $-0.9--0.18$ & 0.004 \\
\hline $\begin{array}{l}\text { Smoking history } \\
\text { pack-yrs }\end{array}$ & 0.003 & 0.003 & $-0.004-0.01$ & 0.4 \\
\hline Sex & -0.14 & 0.19 & $-0.5-0.2$ & 0.5 \\
\hline rs2304566 & -0.37 & 0.12 & $-0.6--0.1$ & 0.002 \\
\hline Age & -0.03 & 0.01 & $-0.05--0.004$ & 0.02 \\
\hline FEV $1 \%$ pred & -0.03 & 0.01 & $-0.05--0.008$ & 0.007 \\
\hline Treatment group ${ }^{\#}$ & -0.52 & 0.19 & $-0.9--0.2$ & 0.005 \\
\hline $\begin{array}{l}\text { Smoking history } \\
\text { pack-yrs }\end{array}$ & 0.003 & 0.003 & $-0.004-0.01$ & 0.4 \\
\hline Sex & -0.17 & 0.18 & $-0.5-0.19$ & 0.4 \\
\hline rs1130866 & -0.23 & 0.1 & $-0.42--0.04$ & 0.02 \\
\hline Age & -0.03 & 0.01 & $-0.05--0.005$ & 0.02 \\
\hline FEV $1 \%$ pred & -0.03 & 0.01 & $-0.05--0.007$ & 0.01 \\
\hline Treatment group ${ }^{\#}$ & -0.50 & 0.2 & $-0.9--0.1$ & 0.008 \\
\hline $\begin{array}{l}\text { Smoking history } \\
\text { pack-yrs }\end{array}$ & 0.003 & 0.003 & $-0.004-0.01$ & 0.4 \\
\hline Sex" & -0.12 & 0.19 & $-0.5-0.3$ & 0.5 \\
\hline rs3024791 & -0.61 & 0.18 & $-1.0--0.3$ & 0.0007 \\
\hline Age & -0.03 & 0.01 & $-0.05--0.005$ & 0.02 \\
\hline FEV $1 \%$ pred & -0.03 & 0.01 & $-0.05--0.008$ & 0.009 \\
\hline Treatment group" & -0.53 & 0.19 & $-0.9--0.2$ & 0.006 \\
\hline $\begin{array}{l}\text { Smoking history } \\
\text { pack-yrs }\end{array}$ & 0.003 & 0.003 & $-0.004-0.01$ & 0.4 \\
\hline Sex" & -0.10 & 0.19 & $-0.5-0.2$ & 0.5 \\
\hline rs2077079 & 0.01 & 0.12 & $-0.2-0.2$ & 0.9 \\
\hline Age & -0.03 & 0.01 & $-0.05--0.004$ & 0.02 \\
\hline FEV $1 \%$ pred & -0.03 & 0.01 & $-0.05--0.005$ & 0.02 \\
\hline Treatment group ${ }^{\#}$ & -0.50 & 0.19 & $-0.9--0.1$ & 0.01 \\
\hline $\begin{array}{l}\text { Smoking history } \\
\text { pack-yrs }\end{array}$ & 0.002 & 0.003 & $-0.004-0.01$ & 0.5 \\
\hline Sex" & -0.1 & 0.19 & $-0.5-0.3$ & 0.6 \\
\hline
\end{tabular}

Cl: confidence interval; FEV1: forced expiratory volume in one second; \% pred: $\%$ predicted. ${ }^{\#}$ : underwent lung volume reduction surgery $=1$ and received medical therapy $=0 ; "$ : male $=1$ and female $=0$.

an increased frequency of hospital admissions (OR 4.9, 95\% CI 1.7-14.4; $p=0.011$ ) for COPD exacerbations and reduced mannose binding lectin levels $(p<0.001)$ [11]. No association was demonstrated between the polymorphisms and COPD susceptibility. TAKABATAKE et al. [12] performed a study of Japanese male COPD subjects for association of four SNPs in three chemokine genes (CCL11, CCL5 and CCL1) with COPD exacerbations. From the analysis of 2 yrs of retrospective data, frequent COPD exacerbations were associated with a CCL1 SNP (rs2282691) under a dominant model of inheritance. The same SNP was associated with mortality in a 30-month prospective evaluation of exacerbations (Cox proportional hazards, OR 5.93, $95 \%$ CI 1.28-27.48; $\mathrm{p}=0.023)$.

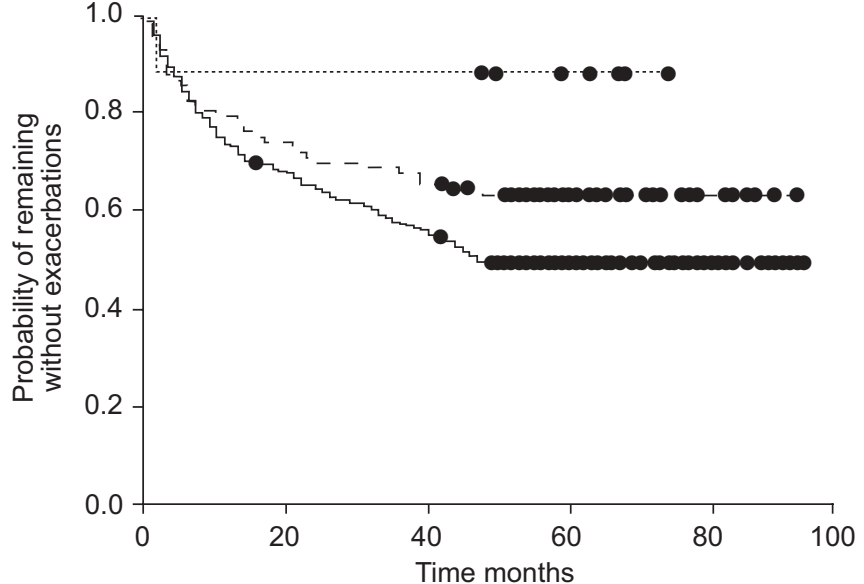

FIGURE 2. Time to chronic obstructive pulmonary disease exacerbation onset for 379 National Emphysema Treatment Trial subjects stratified by surfactant protein B rs3024791 genotype. A log-rank test was used to determine whether two or more survival curves were identical $(p=0.02)$. There were 10 missing genotypes for rs3024791. - _ : zero minor alleles; -----: one minor allele; $\cdots \cdots \cdots$ : two minor alleles.

Pulmonary alveolar surfactant is composed of phospholipids and four surfactant proteins that reduce surface tension and prevent alveolar collapse at low lung volumes. Surfactant protein B promotes adhesion and spreading of surfactant phospholipids and stabilises the phospholipid monolayer [30, 31]. Polymorphisms in $S F T P B$ have been associated with COPD susceptibility in a Mexican population [32] and in a German study [33]. Guo et al. [32] found association between the Thr131Ile polymorphism $(1580 \mathrm{C} / \mathrm{T})$ and COPD susceptibility (OR 3.7, 95\% CI 1.2-12.1; $\mathrm{p}=0.03$ ). SEIFART et al. [33] studied variants in intron 4 (insertions or deletions) in chronic bronchitis or COPD subjects and controls. The only significant difference between the groups was in a subset analysis; variants in intron 4 were more frequent in the COPD subjects with respiratory failure compared to the population-based controls (OR 4.9, 95\% CI 1.8-13.6; $\mathrm{p}=0.003$ ) or the matched controls (OR 3.55, 95\% CI 1.4-9.4; $\mathrm{p}=0.017$ ). HeRsH et al. [13] found significant association of the SFTPB Thr131Ile mutant (rs1130866) with COPD susceptibility in a case-control study of 304 NETT participants and 441 smoking control subjects only in the presence of a gene-by-smoking interaction term $(p=0.01)$. In the Boston Early-Onset COPD Study [13], this SNP was significant in individuals with moderate-to-severe airflow obstruction $(p=0.03)$. A short tandem repeat (D2S388) in SFTPB has also been demonstrated to be associated with the 6-min walk distance, a test for functional impairment, in subjects with severe COPD [19]. Genetic variants in SFTPB have also been reported to be associated with acute respiratory distress syndrome $[34,35]$ and community-acquired pneumonia [36].

Alterations in the hydrophobic surfactant proteins, B and C, are associated with chronic lung disease and acute respiratory distress syndromes that may be due to deficiency of the bioactive surfactant peptides and/or the intracellular accrual of harmful proteins [37]. In addition to the biophysical properties of alveolar stabilisation, improving pulmonary compliance, removal of particulate matter and enhancing 
mucociliary clearance, surfactant and its components have immunological properties [38]. Whether the significant polymorphisms in the present study have qualitative or quantitative impact on surfactant protein B levels or function is not currently known. The Thr131Ile nonsynonymous SNP is located within a functional glycosylation recognition sequence; it has been postulated that alteration of glycosylation could affect the tertiary structure and processing of surfactant protein B [36]. In a study of 53 hospitalised patients with pulmonary and nonpulmonary diseases (28\% COPD), an SFTPB promoter polymorphism, rs3024791, reduced transcriptional activity in transfected cells [39]. This SNP was potentially felt to be a genetic cause for the individual variability in $S F T P B$ mRNA levels. It was not felt to be sufficient to cause surfactant protein B deficiency but could contribute to a loss of function in the presence of multiple mutations or in the presence of a predisposition for lung disease, in combination with other environmental factors. In the present study, rs3024791 was significantly associated with COPD exacerbations and exacerbation frequency.

A unique strength of the present analysis is that an association of surfactant protein B with COPD exacerbation occurrence and frequency was demonstrated; however, the study has limitations. The present study was based on medical claims data, but actual hospital records were not reviewed in order to verify diagnosis coding. The present authors found association with exacerbations significant enough to warrant emergency care or hospitalisation in a medically insured cohort, but did not have data on less-serious exacerbations that only resulted in escalation of medical therapy, such as new prescriptions of antibiotics and/or corticosteroids. The present authors acknowledge that healthcare utilisation varies depending upon access and availability. Additionally, mild exacerbations could be clinically significant and result in emergency room visits or hospitalisation for individuals with severe COPD; all individuals in the present study were GOLD stage III or greater. In the absence of biomarkers that objectively identify COPD exacerbations, an arbitrary threshold of 14 days was used in order to differentiate new from relapsing exacerbations; however, no difference in results was found using a more stringent threshold of 30 days (data not shown). The present study was not designed to determine the effect of the SNPs on surfactant protein B levels or function; although, the findings are a significant addition to the increasing body of evidence for the importance of SFTPB in COPD pathogenesis, the present study's results have not yet been replicated. Additionally, the most significant observations for rs2024791 would withstand the scrutiny of multiple comparisons with five genes but would not meet the more stringent threshold of a Bonferroni correction for 88 SNPs. Finally, the present authors did not formally test for population stratification in their ethnically homogeneous cohort.

In conclusion, the present study provides additional evidence for the importance of single nucleotide polymorphisms in surfactant protein $\mathrm{B}$ in the pathophysiology of chronic obstructive pulmonary disease. An association of chronic obstructive pulmonary disease exacerbations and a potentially functional single nucleotide polymorphism in surfactant protein B was demonstrated. Additional studies are needed to precisely determine the mechanisms by which these variants influence susceptibility to exacerbations. Furthermore, determining the genetic influences on chronic obstructive pulmonary disease exacerbations may ultimately identify individuals at risk and foster the development of new therapeutic targets and treatment strategies.

\section{ACKNOWLEDGEMENTS}

The authors wish to thank J. Abullarade (University of Washington, Seattle, WA, USA), and S. Datta and B.J. Klanderman (both Brigham and Women's Hospital, Boston, MA, USA), for their expert assistance.

\section{REFERENCES}

1 Rabe KF, Hurd S, Anzueto A, et al. Global strategy for the diagnosis, management, and prevention of chronic obstructive pulmonary disease: GOLD executive summary. Am J Respir Crit Care Med 2007; 176: 532-555.

2 Donaldson GC, Seemungal TA, Bhowmik A, Wedzicha JA. Relationship between exacerbation frequency and lung function decline in chronic obstructive pulmonary disease. Thorax 2002; 57: 847-852.

3 Silverman EK. Exacerbations in chronic obstructive pulmonary disease: do they contribute to disease progression? Proc Am Thorac Soc 2007; 4: 586-590.

4 Soler-Cataluña JJ, Martínez-García MA, Román Sánchez P, Salcedo E, Navarro M, Ochando R. Severe acute exacerbations and mortality in patients with chronic obstructive pulmonary disease. Thorax 2005; 60: 925-931.

5 Seemungal TA, Donaldson GC, Paul EA, Bestall JC, Jeffries DJ, Wedzicha JA. Effect of exacerbation on quality of life in patients with chronic obstructive pulmonary disease. Am J Respir Crit Care Med 1998; 157: 1418-1422.

6 Donaldson GC, Wilkinson TM, Hurst JR, Perera WR, Wedzicha JA. Exacerbations and time spent outdoors in chronic obstructive pulmonary disease. Am J Respir Crit Care Med 2005; 171: 446-452.

7 Hilleman DE, Dewan N, Malesker M, Friedman M. Pharmacoeconomic evaluation of COPD. Chest 2000; 118: 1278-1285.

8 Halpern MT, Stanford RH, Borker R. The burden of COPD in the U.S.A.: results from the Confronting COPD survey. Respir Med 2003; 97: Suppl. C, S81-S89.

9 Miravitlles M, Murio C, Guerrero T, Gisbert R, DAFNE Study Group., Decisiones sobre Antibioticoterapia y Farmacoeconomía en la EPOC., Pharmacoeconomic evaluation of acute exacerbations of chronic bronchitis and COPD. Chest 2002; 121: 1449-1455.

10 Celli BR, Barnes PJ. Exacerbations of chronic obstructive pulmonary disease. Eur Respir J 2007; 29: 1224-1238.

11 Yang IA, Seeney SL, Wolter JM, et al. Mannose-binding lectin gene polymorphism predicts hospital admissions for COPD infections. Genes Immun 2003; 4: 269-274.

12 Takabatake N, Shibata Y, Abe S, et al. A single nucleotide polymorphism in the CCL1 gene predicts acute exacerbations in chronic obstructive pulmonary disease. Am J Respir Crit Care Med 2006; 174: 875-885.

13 Hersh CP, DeMeo DL, Lange C, et al. Attempted replication of reported chronic obstructive pulmonary disease candidate gene associations. Am J Respir Cell Mol Biol 2005; 33: $71-78$. 
14 DeMeo D, Mariani T, Lange C, et al. The SERPINE2 gene is associated with chronic obstructive pulmonary disease. Am J Hum Genet 2006; 78: 253-264.

15 Rationale and design of the National Emphysema Treatment Trial (NETT): a prospective randomized trial of lung volume reduction surgery. J Thorac Cardiovasc Surg 1999; 118: 518-528.

16 National Emphysema Treatment Trial Research Group, Patients at high risk of death after lung-volume-reduction surgery. N Engl J Med 2001; 345: 1075-1083.

17 Fishman A, Martinez F, Naunheim K, et al. A randomized trial comparing lung-volume-reduction surgery with medical therapy for severe emphysema. N Engl J Med 2003; 348: 2059-2073.

18 Celli BR, Cote CG, Marin JM, et al. The body-mass index, airflow obstruction, dyspnoea, and exercise capacity index in chronic obstructive pulmonary disease. $N$ Engl J Med 2004; 350: 1005-1012.

19 Hersh CP, DeMeo DL, Lazarus R, et al. Genetic association analysis of functional impairment in chronic obstructive pulmonary disease. Am J Respir Crit Care Med 2006; 173: 977-984.

20 Hersh CP, DeMeo DL, Reilly JJ, Silverman EK. Xenobiotic metabolizing enzyme gene polymorphisms predict response to lung volume reduction surgery. Respir Res 2007; 8: 59.

21 Celedón JC, Lange C, Raby BA, et al. The transforming growth factor-beta1 (TGFB1) gene is associated with chronic obstructive pulmonary disease (COPD). Hum Mol Genet 2004; 13: 1649-1656.

22 Seattle SNPs. http://pga.mbt.washington.edu Date last accessed: 21 July 2008. Date last updated: 10 July 2008.

23 International HapMap Consortium, A haplotype map of the human genome. Nature 2005; 437: 1299-1320.

24 Tagger: Selection and evaluation of tag SNPs. www.broad.mit.edu/mpg/tagger Date last accessed: 21 July 2008. Date last updated: 11 September 2008.

25 Barrett JC, Fry B, Maller J, Daly MJ. Haploview: analysis and visualization of LD and haplotype maps. Bioinformatics 2005; 21: 263-265.

26 Freidlin B, Zheng G, Li Z, Gastwirth JL. Trend tests for case-control studies of genetic markers: power, sample size and robustness. Hum Hered 2002; 53: 146-152.

27 Schaid DJ, Rowland CM, Tines DE, Jacobson RM, Poland GA. Score tests for association between traits and haplotypes when linkage phase is ambiguous. Am J Hum Genet 2002; 70: 425-434.
28 Fan VS, Ramsey SD, Make BJ, Martinez FJ. Physiologic variables and functional status independently predict COPD hospitalizations and emergency department visits in patients with severe COPD. COPD 2007; 4: 29-39.

29 Washko GR, Fan VS, Ramsey SD, et al. The effect of lung volume reduction surgery on chronic obstructive pulmonary disease exacerbations. Am J Respir Crit Care Med 2008; 177: 164-169.

30 Griese M. Pulmonary surfactant in health and human lung diseases: state of the art. Eur Respir J 1999; 13: 1455-1476.

31 Steagall WK, Lin JP, Moss J. The C/A(-18) polymorphism in the surfactant protein $\mathrm{B}$ gene influences transcription and protein levels of surfactant protein B. Am J Physiol Lung Cell Mol Physiol 2007; 292: L448-L453.

32 Guo X, Lin HM, Lin Z, et al. Surfactant protein gene A, B, and $\mathrm{D}$ marker alleles in chronic obstructive pulmonary disease of a Mexican population. Eur Respir J 2001; 18: 482-490.

33 Seifart C, Plagens A, Brödje D, Müller B, von Wichert P, Floros J. Surfactant protein B intron 4 variation in German patients with COPD and acute respiratory failure. Dis Markers 2002; 18: 129-136.

34 Gong MN, Wei Z, Xu LL, Miller DP, Thompson BT, Christiani DC. Polymorphism in the surfactant protein-B gene, gender, and the risk of direct pulmonary injury and ARDS. Chest 2004; 125: 203-211.

35 Lin Z, Pearson C, Chinchilli V, et al. Polymorphisms of human SP-A, SP-B, and SP-D genes: association of SP-B Thr131Ile with ARDS. Clin Genet 2000; 58: 181-191.

36 Quasney MW, Waterer GW, Dahmer MK, et al. Association between surfactant protein $B+1580$ polymorphism and the risk of respiratory failure in adults with communityacquired pneumonia. Crit Care Med 2004; 32: 1115-1119.

37 Whitsett JA, Weaver TE. Hydrophobic surfactant proteins in lung function and disease. N Engl J Med 2002; 347: 2141-2148.

38 van Iwaarden JF, Claassen E, Jeurissen SH, Haagsman HP, Kraal G. Alveolar macrophages, surfactant lipids, and surfactant protein B regulate the induction of immune responses via the airways. Am J Respir Cell Mol Biol 2001; 24: $452-458$.

39 Thomas KH, Meyn P, Suttorp N. Single nucleotide polymorphism in 5'-flanking region reduces transcription of surfactant protein B gene in H441 cells. Am J Physiol Lung Cell Mol Physiol 2006; 291: L386-L390. 